\title{
UM MUNDO FEITO DE PAPEL: SOFRIMENTO E ESTEIIZACĀÃO DA VIDA (OS DIÁRIOS DE CAROLINA MARIA DE JESUS)
}

\author{
Marco Antonio Gonçalves \\ Universidade Federal do Rio de Janeiro - Brasil
}

Resumo: Este artigo revisita os escritos de Carolina Maria de Jesus, em particular o livro Quarto de despejo, com a intenção de pensar sua escrita (e seu próprio ato de escrever) como forma de elaboração de sua condição social de existência. Sua escrita, enquanto automodelagem de sua "pessoa” é construída através de processos de percepção de seu sofrimento social e de instauração de uma aguda consciência de sua corporalidade. Explorando o conceito de sofrimento social, enquanto processo de experiência e cognição, analisa-se o lugar de sua escrita, dolorosamente crítica, na forma como apreende o mundo, como se revela a si mesma e exprime sua revolta ao tomar consciência de sua condição social. Delineia, também, a "corporificação de seu sofrimento social" a partir do conceito "cosmografia da fome”, que ganha na escrita de Carolina uma complexa elaboração de cartografias que fazem coincidir corpo e espaço, territórios urbanos de deambulação e órgãos corporais. Seu sofrimento social se estrutura através da escrita como possibilidade de agência, de revolta e revide que promove os processos de transformação de sua condição social de existência.

Palavras-chave: biografia, corporalidade, sofrimento social, subjetividade.

\begin{abstract}
This article revisits the writings of Carolina Maria de Jesus, in particular her book, Quarto de despejo [Child of the dark in the English edition]. It aims to reflect upon her writing (and her very act of writing) as a mode of elaborating her social condition of existence. The self-fashioning of her 'person' in her writing involves the processual perception of her social suffering and the establishment of a heightened conscience of her corporeality. Exploring the concept of social suffering, as an experiential and cognitive process, the article analyses the role of her painfully critical writing in grasping the world around her, in revealing her own self and in expressing her revolt as she becomes conscious of her social condition. It outlines, as well, the "embodiment of her social suffering" through the concept of a 'cosmography of hunger', which, in Carolina's writing, takes on a complex elaboration of cartographies
\end{abstract}


joining together body and space, urban territories of deambulation and bodily organs. Her social suffering is fleshed out through writing into the possibility of agency, revolt and response, which promotes the transformation of her social condition of existence.

Keywords: biography, corporeality, social suffering, subjectivity.

Este artigo revisita os escritos de Carolina Maria de Jesus, em particular o livro Quarto de despejo, com a intenção de pensar sua escrita (e seu próprio ato de escrever) como forma de elaboração de sua condição social de existência. ${ }^{1}$ Sua escrita, enquanto automodelagem de sua "pessoa" é construída através de processos de percepção de seu sofrimento social e de instauração de uma aguda consciência de sua corporalidade.

A autobiografia, a autoescrita, o processo de construção de uma narrativa sobre o self é uma espécie de autopoiesis (Maturana; Varela, 1980), uma capacidade de os sujeitos produzirem a si próprios através das narrativas (Gonçalves, 2012, p. 22; Passeggi, 2011, p. 147).

A justificava para submeter Quarto de despejo à apreciação da antropologia é dada por Vogt (1983) ao declarar que a escrita de Carolina assume a dimensão de um "realismo etnográfico", ${ }_{2}^{2}$ uma narrativa estética que recria, a partir de sua vida e sua biografia, um mundo social. O biográfico e o social, o individual e o cultural, o objetivo e o subjetivo ${ }^{3}$ estão intrinsecamente inter-relacionados na escrita de Carolina, fundidos pelo seu modo de sofrer que é, também, uma forma particular de conhecer, de estranhar a si mesma e o mundo através de sua escrita.

\footnotetext{
1 A pesquisa em que se insere o presente artigo teve origem no desenvolvimento do argumento e direção do filme documentário, o longa-metragem Das nuvens pra baixo (2014), que tem como ponto de partida os diários de Carolina Maria de Jesus transpostos para a favela da Maré no Rio de Janeiro em que uma atriz da Maré desempenha o papel de Carolina e ao reproduzir trechos do diário engendra um diálogo, após 50 anos, com outras cinco mulheres da Maré que narram suas vidas e seu cotidiano na favela hoje. 2 Vogt (1983) compara a escritura de Carolina à etnografia da pobreza desenvolvida por Oscar Lewis (1961) que parte de biografias com grande riqueza de detalhes para entender as populações marginais no processo de urbanização na Cidade do México.

3 Ver especialmente Gonçalves (2012) para uma revisão bibliográfica e problematização dos conceitos de biográfico e social, de indivíduo e sociedade, de pessoal e cultural, de individuação, de etnobiografia na teoria antropológica.
} 
$\mathrm{Na}$ primeira parte do artigo forneço informações biográficas sobre Carolina Maria de Jesus situando-a no tempo e no espaço. Na segunda parte, "O grapho: conhecer pelo sofrimento", parto de uma conceituação de Das (2006) para realizar uma análise do lugar de sua escrita, dolorosamente crítica, na forma como apreende o mundo, revela a si mesma e exprime sua revolta ao tomar consciência de sua condição social. Mobilizo os conceitos de grapho, eventos críticos, testemunho, sofrimento social como forma de compreender o processo de "construção da pessoa" de Carolina que é atravessada pelas relações de gênero, raça e classe social que, em seus escritos, ganham plena elaboração a partir de uma autorreferência reflexiva como mulher, negra e favelada.

$\mathrm{Na}$ terceira parte, "O corpo, a escrita da dor", procuro apreender a "corporificação de seu sofrimento social" (Víctora, 2011) a partir do que conceituo como "cosmografia da fome", que ganha na escrita de Carolina uma complexa elaboração de cartografias que fazem coincidir corpo e espaço, territórios urbanos de deambulação e órgãos corporais.

Nas considerações finais proponho uma reflexão sobre o tempo estrutural do sofrimento social de Carolina que não é simplesmente construído pela passagem do tempo dos dias e anos em seu diário. A estrutura de seu sofrimento social se realiza através da escrita como possibilidade de agência, revolta, revide que promove os processos de transformação de sua condição social de existência desafiando as configurações da sociedade brasileira dos anos 1960.

\section{Carolina Maria de Jesus ${ }^{4}$}

Nasce em 1914 e morre em 1977, aos 62 anos de idade. Passa sua infância em Sacramento, interior de Minas Gerais, onde aprende a ler cursando até o segundo ano primário. No tempo em que reside em Minas trabalha na roça com a mãe e depois se emprega como doméstica. Em 1937, aos 23 anos, muda-se para São Paulo. Trabalha como empregada doméstica habitando em cortiços na região central da cidade. A partir das reformas urbanas da década de 1940 muda-se em 1948 para a favela do Canindé, às margens do rio Tietê (Silva, 2006, p. 9). A atividade exercida por mais tempo em São Paulo é como

4 Para detalhes e informações biográficas de Carolina recomendo Castro e Machado (2007), Vogt (1983) e Dantas (2012).

Horizontes Antropológicos, Porto Alegre, ano 20, n. 42, p. 21-47, jul./dez. 2014 
catadora de papel pelas ruas da cidade. Deambula pela cidade, produzindo circuitos, trajetos, catando papéis que são convertidos em alimentos de seu corpo e de seu espírito. No mesmo lixo onde cata os papéis para venda encontra os cadernos que se tornam "seus diários", transformam-se em seu "ideal", no objetivo de sua vida. Em 1955 inicia a escrita do que designa seu "estranho diário", onde relata as agruras de seu dia a dia, suas reflexões sobre seu sofrimento, sua fome, sua ira contra os políticos, sua obsessão em transformar sua vida através da escrita, o desejo de escrever um livro e tornar-se escritora. ${ }^{5}$ Sua escrita é cotidiana, segue o ritmo dos dias que coincide com a própria construção e elaboração de uma história de seu sofrimento no cenário da favela. Em 1958 encontra, por acaso, na porta de sua casa um jovem jornalista, Audálio Dantas, que faz uma reportagem sobre a expansão das favelas nas margens do Tietê. Esse encontro revira sua vida e dá visibilidade à sua escrita. A matéria do jornal passa a ser sobre os diários de Carolina. Em 1960, Audálio compila seus diários e Carolina publica seu primeiro livro: Quarto de despejo. O livro vende dez mil exemplares na primeira semana e ganha sucessivas tiragens feitas pela Editora Livraria Francisco Alves, chegando a cem mil exemplares em seis meses.

Quarto de despejo é traduzido em 13 línguas e comercializado em mais de 40 países. Carolina ganha enorme popularidade no Brasil e no exterior no início dos anos 1960. Torna-se a "favelada escritora", "a voz da favela". Porém, seu sucesso editorial dura pouco e é praticamente interrompido com o advento do golpe militar de 1964. Carolina sai da favela, compra uma casa de alvenaria, gasta todo o dinheiro que ganha e pensa em retornar para sua atividade de catadora. Consegue vender sua casa e comprar um sítio em Parelheiros, nos arredores de São Paulo, onde passa a viver como na sua infância, cuidando dos porcos e de uma pequena roça. Depois de Quarto de despejo lança mais dois livros autobiográficos: em Casa de alvenaria escreve sobre sua nova condição social, um relato sobre sua saída da favela, enquanto Diário de Bitita é escrito em forma de recordações de sua infância em Minas Gerais. Escreve, ainda, romances, peças de radionovela, poesias, provérbios,

Silva (2006, p. 12, 2008, p. 77) destaca que mesmo antes de mudar-se para a favela Carolina já desenvolvia seu pendor para a escrita, sobretudo de poemas, e chega a publicar um poema em 1941 no jornal Folha da Manhã, intitulado "O colono e o fazendeiro", que dá conta de seus infortúnios passados na zona rural como trabalhadora nas fazendas no interior de Minas.

Horizontes Antropológicos, Porto Alegre, ano 20, n. 42, p. 21-47, jul./dez. 2014 
grava um disco, também intitulado Quarto de despejo (Jesus, 1961b), com suas próprias composições pela RCA Victor em $1961 .{ }^{6}$

\section{0 grapho: conhecer pelo sofrimento ${ }^{7}$}

Carolina Maria de Jesus foi definida como "grafomaníaca" (Rufino, [s.d.]). Os 140 cadernos, as mais de 4500 páginas escritas, atestam sua compulsão para escrever. A escrita não é escolha, mas destino. É o modo como se situa no mundo, fala da vida, do sofrimento, dos seus maiores personagens: a favela e a fome. "Favela", "fome", "sofrimento" são referências constantes em suas publicações e em seus escritos. O seu "estranho diário", como nomeava seus cadernos, era o suporte material pelo qual Carolina constituía sua "pessoa" pelo trinômio "mulher", "preta", "pobre" atravessando relações de gênero, raça e classe social. Seu "estranho diário" é um modo visceral de tomada de consciência de si e dos outros, de sua cor da pele, do cenário em que vive e pelo qual deambula pelas ruas de São Paulo à cata de papel: "Parece que eu vim ao mundo predestinada a catar. Só não cato a felicidade." (QD, p. 72). ${ }^{8}$ Sua vida é literalmente a de "papeleira", feita de papéis que vende e dos cadernos que escreve. O papel é um devir: meio para encontrar comida e suporte para sua escrita. O papel produz seu corpo e seu espírito, é o que a anima. Carolina tem "fome" de papel: cata e escreve. Sua literatura nasce do lixo, é o seu "achado".

O papel escrito tem um poder transformador e multiplicador: pela escrita Carolina estetiza sua própria vida, ${ }^{10}$ recriando o seu cotidiano em uma vida por escrito. Pela escrita, Carolina é objeto de reflexão, sujeito da ação, pessoa,

6 Para uma visão completa e detalhada da produção textual de Carolina e seus contextos de produção ver Silva (2006).

7 Sigo a conceituação de "conhecer pelo sofrimento" formulada por Das $(2006$, p. 76,80$)$ a partir das reflexões de Nussbaum (1986, p. 46) que percebe "sofrimento" como a condição subjetiva necessária para se produzir o conhecimento, o que não pode ser apreendido apenas através de uma compreensão intelectiva, mas o é em situações definidas como limite ou extremas.

8 As citações de Quarto de despejo adotam o formato de suas iniciais, "QD", indicando em seguida a página correspondente que se refere à referência bibliográfica Jesus (1963). As citações de Jesus foram atualizadas quanto à ortografia.

9 Para a relação entre o papel achado na rua e sua produção escrita, ver especialmente Cabrera (2010).

${ }^{10}$ A definição de estetização da vida, o tornar-se um personagem de si mesmo encontra ressonâncias na proposição de Lukács (1978) sobre a estetização do mundo (e da vida).

Horizontes Antropológicos, Porto Alegre, ano 20, n. 42, p. 21-47, jul./dez. 2014 
personagem, vítima e escritora. Carolina, em seu diário, constrói, exemplarmente, sua condição de vítima, não enquanto objeto passivo de uma violência social sofrida, mas como vitimização agentiva, aquilo que dá inteligibilidade a seu sofrimento (Sarti, 2011, p. 56-57). Sua escrita, portanto, é uma espécie de revide ao mundo, agora, apresentado sob sua perspectiva. Esse é o seu modo de estabelecer o nexo entre "violência estrutural, agência e sofrimento social" (Pussetti; Brazzabeni, 2011, p. 469).

A escrita de Carolina não é da ordem da "escrita documental" (Querido, 2012, p. 885), é uma escrita que possui agência, que a transforma em personagem de sua própria vida-escrita: ela constrói sua escritura como máquina de guerra, modo de produzir simultaneamente uma fala subjetivada e uma voz situada em sua condição social e, por isso, seleciona, copia, ficciona, altera, transcria.

Carolina constrói sua pessoa pela escrita, pela autobiografia que nomeia seu sofrer, como sofre na condição do grapho, ${ }^{11}$ isto é, o modo como ela dá forma à sua vida. Seu grapho não é uma construção de um mundo ficcional, mas um tornar-se seu próprio mundo, seu mundo refeito, o da sua vida, o da favela. Parafraseando Das (2006, p. 7): a escrita para Carolina revela mais sobre ela mesma do que tinha consciência sobre si própria.

Dois "eventos críticos", ${ }^{12}$ por excelência, na vida de Carolina foram sua chegada a São Paulo vindo do interior de Minas Gerais e a adoção de sua nova condição social, a de despejada e favelada. É interessante notar que a própria qualificação da favela como quarto de despejo define já sua condição de despejada da zona central da cidade para as margens do rio Tietê com as reformas urbanas promovidas em São Paulo nos anos 1940 (Silva, 2006, p. 15), nas palavras de Carolina: "Classifiquei a favela de quarto de despejo porque em 1948, quando o Dr. Prestes Maia começou a urbanizar a cidade de São Paulo, os pobres que habitavam os porões foram atirados ao relento." (Jesus, 1961a, p. 181). Nesse sentido, a reconfiguração de seu self a partir do momento em que passa a habitar a favela instaura novos modos de ação e sua escrita é a forma de elaborar a redefinição de suas categorias tradicionais de apreensão

11 Adiante desenvolvo o conceito de grapho a partir da discussão de Das $(2006$, p. 8) a propósito do conceito formulado por Derrida (1976, p. 70).

12 Das $(1995,2006$, p. 134) define "eventos críticos" como algo que instaura novos modos de ação, redefinindo as categorias tradicionais de operar o mundo.

Horizontes Antropológicos, Porto Alegre, ano 20, n. 42, p. 21-47, jul./dez. 2014 
do mundo e das relações sociais. Carolina está situada no epicentro de uma grande transformação por que passa a sociedade brasileira nos anos 1950. Seu diário é um testemunho desse processo de urbanização crescente das grandes cidades, das migrações internas, das mudanças dos padrões comportamentais. Carolina começa escrever seu diário em 1955, ano que coincide com e eleição de Juscelino Kubitschek como presidente da república. A Era JK, como ficou conhecido esse momento da história do Brasil, apoiava-se em um discurso que vislumbrava um "caminho para o desenvolvimento" através do processo de industrialização, com a promessa de solução das injustiças sociais na sociedade brasileira (Skidmore, 1979, p. 207 apud Alonso; Toniosso, 2009, p. 4). Carolina em seu diário contrasta a ideologia desenvolvimentista de JK com sua condição de vida na favela, o que a impede de nutrir simpatias pelo presidente: “[...] o que o senhor Juscelino tem de aproveitável é a voz. Parece um sabiá $[\ldots]$ residindo na gaiola de ouro que é o Catete. Cuidado sabiá, para não perder esta gaiola, porque os gatos, quando estão com fome, contemplam as aves nas gaiolas. E os favelados são os gatos. Têm fome." (QD, p. 30).

Carolina vive em São Paulo a experiência inquietante da modernidade, ao colocar em xeque seus princípios tradicionais de ordenar o mundo, é obrigada a viver um processo de individuação, de autonomia que é transformado em seu desafio de sobrevivência. As sensações de abandono, de solidão, ${ }^{13}$ de não poder contar com nada ou ninguém a não ser com seu próprio corpo são definidoras de sua experiência que engendra seu sofrimento social.

A noção de sofrimento social é bastante oportuna para se pensar a dimensão da escrita nos diários de Carolina, sobretudo quando esse sofrimento se cristaliza na categoria onipresente em seu discurso sobre o mundo: a fome. A "fome" de Carolina aponta para a inseparabilidade das esferas da vida pois é, ao mesmo tempo, "física, psicológica, mental e espiritual"14 engendrando uma "forma corporificada de sofrimento" (Víctora, 2011, p. 4).

A experiência brasileira moderna desencadeia o processo autobiográfico de Carolina como modo de dar conta de sua nova constituição no meio urbano. Das (1994, p. 57) define a experiência moderna na Índia contemporânea como

\footnotetext{
13 "Refleti: preciso ser melhor com os meus filhos. Eles não têm ninguém no mundo a não ser eu. Como é pungente a condição de mulher sozinha sem um homem no lar.” (QD, p. 19).

14 Para uma concepção de sofrimento social como "fato social total" ver Pussetti e Brazzabeni (2011, p. 470).
} 
produtora de profunda ambiguidade, responsável por instaurar novos regimes de subjetivação. A escrita de Carolina é produzida por/na ambiguidade de sua nova condição social: suas críticas, objeções, intransigências à moralidade da vida na favela são elaboradas como uma tentativa de se "reformar". ${ }^{15}$ Faz, assim, uma síntese entre os novos padrões comportamentais urbanos e suas convicções culturais ancoradas em um mundo tradicional rural. Sua crítica aos aspectos morais da vida social na favela (alcoolismo, brigas de casais, intrigas, traição, maus-tratos dos filhos) incide sobre os papéis de gênero, recaindo sobre as mulheres, que ganham os qualificativos de "intrigueiras", "bagunceiras", "as cigarras da favela". ${ }^{16}$ Um episódio do seu diário que ilustra bem esse ponto é quando Carolina diz a seu vizinho: "Mas a tua mulher é muito preguiçosa!", seguido dos comentários “ele é quem carrega água, acende o fogo e faz o café, põe o feijão no fogo. É muito mais bonito ver uma mulher disposta do que uma letárgica, igual a tartaruga. Eu não gosto das mulheres preguiçosas." (Jesus, 1996, p. 54). Em outra ocasião diz que na favela "as bagunceiras são as mulheres [...] os homens são mais tolerantes, mais delicados" (QD, p. 18).

Em seus escritos, percebe-se o exato momento em que Carolina, criticando as "mulheres da favela", tema recorrente em seus escritos, passa a incluir a si mesma, reconhecendo sua nova condição social, o que a faz recontextualizar sua crítica: "Devo incluir-me, porque eu também sou favelada. Sou rebotalho. Estou no quarto de despejo, e o que está no quarto de despejo ou queima-se ou joga-se no lixo." (QD, p. 33).

Olhemos mais de perto como sua escrita acontece no contexto de produção da sua individualidade. Seus diários são o modo de situar o novo ambiente, de transformar a favela (como exterioridade) em uma interioridade. Sua escrita não é apenas uma expressão de sua subjetividade mas um modo de produção do sujeito, a condição de sua própria experiência no mundo (Das, 1994, p. 53, 2006, p. 4). ${ }^{17}$ A construção do personagem Carolina através da escrita como um modo de potencializar sua agência se revela na atitude de Carolina frente aos seus escritos, vendo-os como um modo de redenção, de acabar com

\footnotetext{
15 “Eu fiz uma reforma em mim. Quero tratar as pessoas que eu conheço com mais atenção. Quero enviar um sorriso amável às crianças e aos operários.” (QD, p. 25).

16 Alusão à fábula da cigarra e da formiga: "as cigarras da favela" são as mulheres que vivem para se divertir, beber e que não pensam na casa, no marido e nos filhos.

17 Para esta formulação Das segue diretamente as proposições de Wittgenstein (1932, proposições 5.61 e 5.62).
} 
seu sofrimento, de sair da favela, de ter uma "casa de alvenaria". Se a escrita engendra o "quarto de despejo", localização espacial de sua condição social na favela, pode, também, tornar possível a emergência da "casa de alvenaria", outra espacialidade que nomina seu segundo livro baseado em seus diários. $\mathrm{O}$ ato de escrever cria elos possíveis entre o mundo da vida e o mundo da escrita. A escrita a faz reviver aquele seu mundo, mas o revive no grapho. O sentido de grapho sintetiza bem o escrever de Carolina: não é propriamente escrita ou letra, mas a força mesma de um traço que produz sua inscrição no mundo.

Carolina tinha plena consciência de que sua escrita é mais do que sua revolta, mais do que seu grito ou pedido de socorro. É, sobretudo, uma forma de dar-se conta de sua própria existência, ressignificando seu cotidiano de catadora de papel como evento extraordinário através da escrita. Sua escrita, ao reviver os acontecimentos passados, seus infortúnios, suas peripécias, seus descontentamentos, suas felicidades ganha forma catártica, ritualiza-se.

Cavell (2006, p. xiv) relaciona a noção de catarse, proposta por Aristóteles para explicar os efeitos da tragédia, ao ato de testemunhar dando, assim, maior precisão ao conceito de testemunho estabelecido por Das (2006): momento de purgação e purificação das emoções cujo efeito é a produção de uma renovação e restauração. Nada mais adequado para se pensar o sentido do diário de Carolina como ato de testemunho que recria sua vida na escrita de forma sinestésica ao invocar emoções, sensações, expressões (Alonso; Toniosso 2009, p. 3). O seu testemunho é a "criatividade de sua vida", vivida nessa dimensão estética de seus escritos que purgam e purificam as emoções a partir de uma relação estreita entre violência e subjetividade (Das, 2006, p. 60, 78, 237). Esse estado catártico do escrever produz clarões, lampejos de reflexão sobre sua condição de sujeito biográfico e social. Subjetividade para Carolina é a condição mesma de sua escrita, um modo de falar de si para falar da favela, para chegar ao mundo, à política, às injustiças sociais.

Carolina situa a favela como a protagonista de seu diário. Mais do que um cenário em que se desenrola seu "drama", ${ }^{18}$ é sua grande interlocutora, transforma-se em entidade corporificada através de sua escrita. A favela é escrita e descrita como fonte de seu sofrimento, como espaço da precariedade e do abandono que deveria ser superado para se alcançar a felicidade. A favela

18 Desenvolvo adiante esta acepção de "drama" na escrita e na vida de Carolina. 
falada pela escrita de Carolina é a sua própria revolta: "Havia pessoas que nos visitava e dizia: credo, para viver num lugar assim só os porcos. Isto aqui é o chiqueiro de São Paulo. [...] Eu estou começando a perder o interesse pela existência. Começo a me revoltar. E a minha revolta é justa." (QD, p. 30); "Eu classifico São Paulo assim: o Palácio é a sala de visita. A Prefeitura é a sala de jantar e a cidade é o jardim. E a favela é o quintal onde jogam os lixos." (QD, p. 28).

Sua escrita ganha potência ao construir um antagonismo entre seu sofrimento na vida real, como catadora, e o que estaria fora da favela, em outro espaço ou no domínio de sua própria imaginação. Nessa acepção seu sofrer é escrito em seu diário sob a condição de uma fantasia que, segunda ela mesma, é o que garante que suporte sua condição de existência. Enquanto escreve seu próprio drama social, quer estar em outro lugar e por isso o recria em sua imaginação:

Eu deixei o leito às 3 da manhã porque quando a gente perde o sono começa pensar nas misérias que nos rodeia. [...] Deixei o leito para escrever. Enquanto escrevo vou pensando que resido num castelo cor de ouro que reluz na luz do sol. Que as janelas são de prata e as luzes de brilhantes. Que a minha vista circula no jardim e eu contemplo as flores de todas as qualidades. [...] É preciso criar este ambiente de fantasia, para esquecer que estou na favela. Fiz o café e fui carregar água. Olhei o céu, a estrela D'alva já estava no céu. Como é horrível pisar na lama. As horas que sou feliz é quando estou residindo nos castelos imaginários. (QD, p. 52).

[...] contei para D. Angelina que eu havia sonhado que tinha comprado um terreno muito bonito [...]. Ela disse-me que só mesmo no sonho é que podemos comprar terrenos. A coisa mais linda é o sonho. Achei graça nas palavras da D. Angelina, que disse-me a verdade. O povo brasileiro só é feliz quando está dormindo. (QD, p. 120).

Sua imaginação e seu sonho são, sobretudo, recriação dos espaços reais da cidade em que habita ao estabelecer uma consistente oposição entre as margens e o centro de São Paulo. Constrói uma favela como espaço fora da cidade, enquanto recusa de cidade:

Às oito e meia da noite eu já estava na favela respirando o odor dos excrementos que mescla com o barro podre. Quando estou na cidade tenho a impressão que

Horizontes Antropológicos, Porto Alegre, ano 20, n. 42, p. 21-47, jul./dez. 2014 
estou na sala de visita com seus lustres de cristais, seus tapetes de veludos, almofadas de cetim. E quando estou na favela tenho a impressão que sou um objeto fora de uso, digno de estar num quarto de despejo. (QD, p. 33).

A "periferia" de São Paulo nos anos 1950 estava às margens do rio Tietê. Um circuito é traçado pelos passos de Carolina em seu trajeto em busca de papel para venda nos depósitos; percorrer esse espaço é o que garantia sua sobrevivência. ${ }^{19} \mathrm{O}$ circuito de suas deambulações faz coincidir regiões geográficas com espaços de sofrimento e de felicidade. Assim, os escritos de Carolina são como que cartografias do sofrimento inscritas em um determinado circuito da precariedade urbana. Sua existência ganha a mesma dimensão de precariedade do espaço que habita, sua vida é descrita do mesmo modo que a favela: "sucursal do inferno ou o próprio inferno" (QD, p. 145).

$\mathrm{Na}$ escrita de Carolina a favela ganha a dimensão de um espaço diabolizado, onde se enfrentam as agruras da vida, onde os infelizes perambulam por um mundo insípido, em que se sente um frio exterior e interior, em que se tem vontade de morrer: "Por isso que eu digo que a favela é o Gabinete do Diabo. [...] Fiz o almoço, depois fui escrever. Estou nervosa. O mundo está tão insípido que eu tenho vontade de morrer. Fiquei sentada no sol para aquecer. Com as agruras da vida somos uns infelizes perambulando aqui neste mundo. Sentindo frio interior e exterior." (QD, p. 157).

A favela enquanto "sucursal do inferno" e "gabinete do diabo" encontra muitos paralelos nas etnografias que descrevem situações de sofrimento social. O sofrimento é associado ao espaço em que o diabo habita. É o caso dos camponeses bolivianos descritos por Taussig (2010, p. 42), que pensam as minas e os canaviais como espaço do diabo e do mal, qualificativos que engendram uma singular metafísica do modo de produção capitalista. $O$ vapor do diabo (Leite Lopes, 1978) é a poderosa metáfora proposta por um operário turbineiro da Usina de Açúcar Catende para expressar a condição de existência em um espaço onde "só pode trabalhar o diabo". Zaluar (1994, p. 11) condensa toda a violência, sofrimento e revolta em uma frase proferida por um de seus jovens entrevistados quando narra sua existência através das armas e drogas na Cidade de Deus: "este é o condomínio do diabo". A figura

19 Para os conceitos de trajeto, circuito, pedaço ver Magnani (2002, 2009). Ver Ciavatta (2013, p. 135) para o circuito de Carolina e seu mapa da precariedade na São Paulo dos anos 1950. 
do diabo e o território do inferno abundam como imagens da favela escritas por Carolina: "A favela é uma cidade esquisita e o prefeito daqui é o Diabo." (QD, p. 81); "Estou tão triste! Se eu pudesse mudar desta favela! Isso é obra do Diabo." (QD, p. 154); "Cheguei no inferno." (QD, p. 13); "Se eu pudesse mudar desta favela! Tenho a impressão que estou no inferno." (QD, p. 24); "Eu estava com nojo de retornar a favela. Mas precisava voltar, porque havia deixado os meus filhos. Quando eu descia para o Inferno..." (QD, p. 140).

A associação estabelecida por Carolina entre favela, inferno e diabo dá conta, simultaneamente, de uma existência automodelada pelo sofrimento e uma revolta contra o próprio sofrimento. Em uma passagem de seu diário ela mesma faz um trocadilho com seu nome "Carolina de Jesus" ao escrever, exaltada, sobre um rapaz que tentou abusar sexualmente de sua filha. Diz que vai dar uma surra no tal rapaz, diz que é corajosa e justifica seus atos: "Na minha terra o meu apelido é Carolina do Diabo!" (Jesus, 1996, p. 109). A metafísica do mal e a favela diabolizada, longe de ser uma alienação sobre sua condição de vida, é um poderoso modo de Carolina elaborar uma consciência dolorosamente crítica. ${ }^{20}$ Transforma sofrimento em revolta e a ira do diabo e as profundezas do inferno surgem como forças retóricas expressivas em sua narração sobre si mesma e sobre a favela: "Eu sim! É que sei viver na favela. Quando é preciso ser sensata eu sou. Quando é preciso ser louca eu sou [...]. Quando eu vim residir aqui na favela eu era suave [...]. Atualmente sou pior que soda cáustica." (Jesus, 1996, p. 111, 115).

$\mathrm{Na}$ escrita sua revolta ganha dramaticidade, condensando-se em narrativas sobre os políticos, transbordando sua vida, inundando a cidade e a sociedade como cortes à faca, assassinatos, atos viscerais que expressam sua dor. Esse escrever como ato, proposto por Carolina em seu diário, junta, de uma só vez, representação e ação presentificando em sua escrita seu sofrimento como agência. Suas palavras queimam, matam, enforcam, picam, repicam, rasgam, surram: "Vi um jornal com o retrato da deputada Conceição da Costa Neves, rasguei e pus no fogo. Nas épocas eleitorais ela diz que luta por nós." (QD, p. 100); "Eu quando estou com fome quero matar o Jânio, quero enforcar o Adhemar e queimar o Juscelino. As dificuldades cortam o afeto do povo pelos políticos." (QD, p. 29).

${ }^{20}$ Do mesmo modo que Taussig (2010, p. 43) associa a construção da figura do diabo à consciência crítica sobre o capitalismo elaborada pelos camponeses bolivianos. 
Carolina emprega com frequência "drama", na acepção de novela, do desenrolar da vida diária relacionando, naturalmente, o seu diário ao modo narrativo dos "dramas do rádio", as peças radiofônicas dos anos $1950 .{ }^{21} \mathrm{O}$ drama do rádio a impulsiona a escrever o seu próprio "drama", seu diário: "Liguei o rádio para ouvir os dramas. Fiz o almoço e deitei. Dormi uma hora e meia. Nem ouvi o final da peça. Comecei fazer o meu diário.” (QD, p. 23).

Carolina tinha plena consciência do significado de sua escrita: o de transpor uma vida para a forma escrita na pura acepção do conceito de mimese pensada enquanto obra de arte: ${ }^{22}$ uma transposição do real através das palavras (Gefen, 2003, p. 14). A construção de um eu/narradora de si mesma/do mundo assume nos diários de Carolina sua melhor expressão na forma do "discurso indireto livre" (Hamburger, 1986, p. 93), o que produz uma conivência entre o discurso do narrador e de seus personagens, quando o autor faz coincidir um "eu", Carolina, equivalente a um "nós", favelados. O sofrer é o responsável por esta fusão ao proporcionar uma identificação de um eu pessoal que sofre com a condição social do sofrimento: "Aqui na favela quase todos lutam com dificuldades para viver. Mas quem manifesta o que sofre é só eu. E faço isto em prol dos outros." (QD, p. 32).

Sua potência discursiva não consiste somente em reproduzir indiretamente suas próprias falas ou as de seus personagens, mas dá vazão a um real imaginado pela própria narradora que evoca através de sua escrita os seus sonhos (e os dos outros), os seus desejos (e os dos outros). Dessa forma sua escrita assume a excelência da qualidade mimética em relação ao mundo, recria-o de forma táctil, sensorial e experiencial (Benjamin, 1985; Taussig, 1993), recriação que não quer apenas representá-lo, pois o expressa borrando as fronteiras entre o que seria o plano da subjetividade de seu sofrimento e o da inteligibilidade de sua condição social. Sua escrita é mimese de seu próprio mundo, a favela e seus personagens. Recria enquanto copia, transforma sua própria vida pela agência da escrita. Se sua fala no cotidiano é silenciada pelo seu sofrimento e condição social, sua escrita dá conta

${ }^{21}$ Drama, enquanto novela de rádio, foi um dos gêneros adotados por Carolina. Escreveu algumas peças, hoje ainda manuscritas no acervo da Biblioteca Nacional no Rio de Janeiro.

22 Fenandez (2008, p. 143) chama atenção para esta "atualização de elementos de ficção" na obra de Carolina, o que a retira de um tratamento documental ou como crônica sobre a miséria. Para uma avaliação da estética de sua poética ver Lajolo (1996).

Horizontes Antropológicos, Porto Alegre, ano 20, n. 42, p. 21-47, jul./dez. 2014 
do indizível, daquilo que somente pode ser narrado se transposto para as páginas de seus cadernos. Seu sofrimento, portanto, é da ordem da escrita, o único modo dele ser evocado, de ser compreendido e apreendido por Carolina. Seus cadernos, eles mesmos, podem ser comparados a uma pintura expressionista de sua vida feita com garranchos, letras, inscrições, sujeira guardada em seu suporte, nos papéis, toda a manifestação de seu grapho. Derrida (1976, p. 70) concebe grapho não como a escrita, a letra, mas como gesto, visualidade, musicalidade, um conceito de grapho que parece se aplicar plenamente à potência criativa de Carolina, que insiste em deixar no mundo seu traço inscrito em seus diários, suas fotos, suas composições, sua voz em seu disco gravado (Jesus, 1961b). Carolina produz uma "voz", no sentido atribuído por Das que repensa os conceitos de escrita formulado por Derrida (Das, 2006, p. 8): sua "voz" não se confunde com a fala e não é constituída em oposição à escrita em um jogo de presença e ausência. A escrita de Carolina engendra esta relação entre seu cotidiano e a produção de sua "voz" (Das, 2006, p. 2): o seu diário é o modo como ela inscreve a passagem do tempo a partir da microproliferação de "eventos críticos" (Das, 1995). Entendemos assim a insistência de Carolina em escrever, por este ser o seu duplo drama, o de sua vida e de sua literatura: "Hoje, estou reiniciando a escrever o meu diário, creio que não poderei viver sem escrever porque os dramas continuam a acontecer enquanto vivemos..." (Jesus, 1996, p. 54). Sua escrita narra seus dramas, ganhando a existência de uma resistência. Um modo pelo qual Carolina não apenas elabora, mas vive seus infortúnios, fazendo transbordar seu silêncio de humilhação e condição social em uma escrita revoltada.

Essa condição de revolta pelas agruras da vida ganha potência quando Carolina escreve sobre os ensinamentos que recebe de Frei Luiz, que diz para as pessoas que estas têm de ser humildes. Carolina revida pela escrita:

[...] se o Frei Luiz fosse casado e tivesse filhos e ganhasse salário mínimo, aí eu queria ver se o Frei Luiz era humilde. Diz que Deus dá valor só aos que sofrem com resignação. Se o Frei visse os seus filhos comendo gêneros deteriorados, comidos pelos corvos e ratos, havia de revoltar-se, porque a revolta surge das agruras. (QD, p. 76).

O episódio em que sofre discriminação pela caixa do açougue é significativo. Carolina entra no açougue e pergunta se tem banha. Percebe que a caixa 
lança sobre ela um "olhar descontente" e responde "não, não tem banha". Carolina insiste, pergunta se tem carne e recebe a mesma negativa. Entra outro cliente que pergunta se tem banha, a caixa espera Carolina sair do açougue para dizer que tem. Carolina retorna para a favela furiosa questionando: "Então o dinheiro do favelado não tem valor?" Pensa em vingar-se, mas de que modo? Através da escrita: "Hoje eu vou escrever e vou xingar a caixa desgraçada do Açougue Bom Jardim. Ordinária!” (QD, p. 132-133).

Sua escrita dá conta da sua condição no mundo, do seu sofrimento silenciado que se revolta e ganha voz pela letra. Seu silêncio vivido como violenta subordinação ao mundo, que lhe aprisiona em sua condição de pobre e favelada é rompido através de sua criação libertadora, sua invenção do ato de escrever: "Quando fico nervosa não gosto de discutir. Prefiro escrever. Todos os dias eu escrevo. Sento no quintal e escrevo." (QD, p. 19).

A escrita torna-se a razão de viver, sua defesa, seu ataque: o modo como constrói sua pessoa modelando e sendo modelada pelo sofrimento que, para Carolina, se resume no próprio ato de viver: "não há coisa pior na vida do que a própria vida" (QD, p. 145).

Essa recusa do mundo pelo ato de escrever é o modo através do qual Carolina expressa seu ideal, sua busca, seu projeto de vida e de transformação. Quando um dos seus namorados, o "Senhor Manuel", a pede em casamento, ela o rejeita para continuar sua escritura do mundo. Reflete: "[...] um homem não há de gostar de uma mulher que não pode passar sem ler. E que levanta para escrever. E que deita com lápis e papel debaixo do travesseiro. Por isso é que eu prefiro viver só para o meu ideal." (QD, p. 44). Carolina assume a condição de "renunciante" em favor da escrita (Dumont, 1985, p. 38), pois a escrita é o que lhe assegura uma alteridade essencial com a favela, com sua vida, com seu sofrimento. Viver para escrever e escrever para viver é o seu modo de renunciar ao mundo.

Esse seu estar fora-do-mundo pela escrita era percebido pelos moradores da favela que entendiam seu ato de escrever como negação e distanciamento daquele mundo. Sua escrita era condenada e, ao mesmo tempo, temida: "Sentei ao sol para escrever. A filha da Silvia, uma menina de seis anos passava e dizia: Está escrevendo, negra fedida! A mãe ouvia e não repreendia. São as mães que instigam.” (QD, p. 24). Carolina, em represália a essa ofensa, parte para o ataque, transformando sua escrita em um modo de revide, assumindo a posição de estar fora daquele mundo: "Vocês são incultas, não podem 
compreender. Vou escrever um livro referente a favela. Hei de citar tudo que aqui se passa. E tudo que vocês me fazem. Eu quero escrever o livro, e vocês com estas cenas desagradáveis me fornecem os argumentos." (QD, p. 17). Em seguida diz que Silvia, mãe da menina que a xingou pediu para "retirar o seu nome do meu livro" (QD, p. 17). O seu diário era a prova de que Carolina tinha criado uma poderosa arma contra seu sofrimento, um distanciamento necessário daqueles que no seu entender eram responsáveis pelo seu sofrer: a favela e os favelados.

Carolina passa a manipular sua atividade de escrever como modo de produzir sua própria estranheza e estranhamento: "As rascoas da favela estão vendo eu escrever e sabem que é contra elas. Resolveram me deixar em paz." (QD, p. 18). Muitas pessoas a incitavam a colocar todos que agiam incorretamente em seu diário, outras tinham medo de entrar em "seu estranho diário": "Os homens vagabundos querem tirar a bola das crianças. Os meninos jogam pedras nos marmanjos. Eles querem bater nas crianças. Quando me veem ficam quietos porque ninguém quer entrar no meu estranho diário.” (QD, p. 54).

Seu sofrimento expresso pela escrita assume esta potência revolucionária de poder transformar o mundo pelas palavras, de transformar sua vida e a dos outros. O poder contagiante e denunciativo de sua escrita é atestado em uma passagem em que conta que quando passava pela Avenida Tiradentes, alguns operários que deixavam a fábrica disseram para Carolina: "Já que você gosta de escrever, instiga o povo para adotar outro regime.” (QD, p. 100). Em seguida o mesmo operário explicita a condição de seu sofrimento, a fome, o que confirma que sua escrita é percebida como um modo de dar conta de seu sofrimento. O operário lhe pergunta: "É verdade que você come o que encontra no lixo?" Carolina responde: "O custo de vida nos obriga a não ter nojo de nada. Temos que imitar os animais.” (QD, p. 100).

\section{0 corpo, a escrita da dor}

Wittgenstein (1958, p. 49) recuperado por Das (2006, p. 39-40) propõe uma figuração sobre dor e corporalidade:

Suponham que eu sinto uma dor que, dada unicamente a evidência da dor, por exemplo, com os olhos fechados, eu chamaria uma dor na minha mão esquerda. Alguém me pede para tocar o lugar doloroso com a minha mão direita. Faço-o

Horizontes Antropológicos, Porto Alegre, ano 20, n. 42, p. 21-47, jul./dez. 2014 
e ao olhar em volta apercebo-me de que estou a tocar na mão de uma pessoa que se encontra perto de mim... a idéia de sentir dor no corpo de outra pessoa. ${ }^{23}$

Essa formulação sobre o sentir a dor de outro corpo parece ser uma possibilidade de criar uma percepção cognitiva através da subjetividade e da experiência de outrem. A escrita de Carolina realiza esta possibilidade de "sentirmos a dor no seu corpo".

A dor, a fome, a precarização da vida, a indefinição de um futuro imediato, a falta de dinheiro e a luta para criar os filhos e se manter viva seriam os elementos constitutivos da corporificação de seu sofrimento. Essa forma de conceituação do corpo como construído pela escrita dolorosa e ao mesmo tempo redentora de Carolina se aproxima da concepção formulada por Víctora $(2011, \text { p. } 5)^{24}$ de sofrimento social "que não apenas se expressa mas, fundamentalmente, se experimenta no corpo".

Seu corpo dói, tem fome, anda, se cansa, cata, transpira, sua, fede e escreve. Seu corpo é produto e é produzido pelo entrelaçamento de suas práticas diárias. Carolina é prisioneira de um vaivém infinito que nunca cessa: precisa de seu corpo para catar papel que por sua vez é transformado em combustível (físico e mental) para seu corpo. Seu corpo como máquina dá sinais de desgaste em suas engrenagens, mas deve sempre continuar: deambular, andar, doer, produzir.

São inúmeras as referências de Carolina ao seu corpo como infraestrutura que sustenta sua vida, como um lócus que totaliza a produção de sua consciência do mundo. É o seu corpo, concebido como infraestrutura, como tudo que resta a ela, o que a determina pelo prazer e pela dor, que Carolina nos oferece. Uma possibilidade de aceder à sua experiência no mundo e através de seu corpo nos situarmos em seu mundo. ${ }^{25}$

Carolina usa metáforas maquinais para falar da potência e da falibilidade de seu corpo: "Agora eu estou disposta. Parece que trocaram as peças do meu corpo.” (QD, p. 102); “A comida no estômago é como o combustível nas máquinas. Passei a trabalhar mais depressa. O meu corpo deixou de pesar.

23 Tradução retirada de Wittgenstein (1992, p. 91).

24 Em diálogo com Csordas (1994).

${ }_{25}$ Castro e Machado (2007) chamam atenção para o lugar do corpo como um artefato da escrita de Carolina sobre a favela. 
Parece que eu estava comendo pela primeira vez na minha vida." (QD, p. 40). O corpo de Carolina é máquina-órgão seguindo aqui a acepção deleuziana:26 máquina de andar, máquina de comer, máquina de catar, máquina de escrever.

A comida para Carolina é uma literalidade, é combustível. Daí sua urgência em ter o que comer, seu desespero em relação à fome. Em Quarto de despejo a fome é figurada como cosmografia, o desenho uma região no mundo, a favela, e em seu corpo, seu estômago. Carolina a remarca a cada duas páginas, escreve 70 vezes a palavra "fome" produzindo múltiplas associações. Múltipla e única, reiterativa, ecoa no leitor insistentemente: fome, fome, fome, fome... Seu reverso, "comida", Carolina a faz, também, ecoar: "A frase comida ficou eclodindo dentro do meu cérebro. Parece que o meu pensamento repetia: Comida! Comida! Comida!" (QD, p. 153).

A fome é impulso para viver e vontade de morrer. Carolina ao dizer que não desiste da vida se pergunta: "Quero ver como é que eu vou morrer." E responde com a linguagem fisiológica da fome: "Ninguém deve alimentar ideia de suicídio." (QD, p. 55, grifo meu). Dois dias depois retorna ao mesmo tema em seu diário: "Hoje não temos nada para comer. Queria convidar os filhos para suicidar-nos. Desisti. Olhei meus filhos e fiquei com dó. Quem vive, precisa comer." (QD, p. 153). O tema do suicídio é recorrente e a desistência de fazê-lo a impulsiona a justificar uma redefinição de seu mundo quando passa a aceitar a ideia de comer lixo: "Quando eu encontro algo no lixo que eu posso comer, eu como. Eu não tenho coragem de suicidar-me. E não posso morrer de fome." (QD, p. 141).

Carolina insiste em afirmar que a fome não é seu lamento, é seu sofrimento no sentido de que lhe ensina, "a fome é professora" (QD, p. 26), a fome é uma "sinfonia" (QD, p. 56), "é preciso conhecer a fome para saber descrevê-la" (QD, p. 26). No dia 13 de maio de 1958, a fome é figurada em seu diário enquanto tomada de consciência de sua condição social: "Luto contra a escravatura atual - a fome!" (QD, p. 27).

A fome é sua droga: "A tontura da fome é pior do que a do álcool. A tontura do álcool nos impele a cantar. Mas a da fome nos faz tremer.” (QD, p. 39). Uma enfermidade que a faz cair, sentir dor, ver-se no espelho e se perceber magra, sem dentes com medo de morrer (QD, p. 153). A fome é identificada

${ }^{26}$ Ver especialmente o capítulo 1, “As máquinas desejantes” (Deleuze; Guattari, 2010). 
no seu corpo, é um sinal, conforme narra o episódio em que tropeça e cai na rua perto da banca de jornal. Um homem que passava gritou: "É fome!" (QD, p. 88) e lhe dá uma esmola. Suas pernas, pés, rins, peito doem, mas sabe que sua "enfermidade é física e moral" 27 (QD, p. 81). Carolina quando se refere à sua "fome moral" pensa nas agressões proferidas por uma mulher da favela que diz que ela fede igual a bacalhau: "O corpo humano não presta. Quem trabalha como eu tem que feder!" (QD, p. 119). Pensa na rejeição que sofre dos donos de circo quando não aceitam as peças que escreve alegando: "pena que você é preta". Carolina reage: "Eu adoro a minha pele negra, e o meu cabelo rústico. Se é que existe reencarnação, eu quero voltar sempre preta." (QD, p. 58). Quando um homem bem vestido a olha com "repugnância" por estar descalça, suja e carregando um enorme saco de papel, diz: "Já estou familiarizada com estes olhares. Não entristeço.” (QD, p. 98).

\section{0 tempo estrutural do sofrimento social}

O diário de Carolina encarna a duração de um tempo estrutural. Não é uma sucessão dos dias, é condição de existência que encerra passado, presente e futuro. Um tempo do sofrimento que aponta para um devir. Seu diário querendo narrar o que "não é mais" narra seu desejo de ser escritora, de aceder a esta transformação. Quanto mais escreve, faz uma aposta em escrever mais. Ao narrar o que se passou, revive o narrado no momento presente da escrita e adiciona o futuro que é a própria condição crítica de sua existência, tomada de consciência como possibilidade de deslocamento: sair da favela, ser escritora, ter uma casa de alvenaria. Carolina se lembra de sua vontade, quando pequena, de ser homem com a intenção de defender o Brasil. Nos livros de história que lia encontrava apenas nomes masculinos. Sua mãe dizia que se passasse debaixo do arco-íris viraria homem. Carolina, toda vez que via um arco-íris corria em sua direção, mas logo, concluiu: "o arco-íris foge de mim" (QD, p. 48). A metáfora do arco-íris equivale a seu desejo de transformação e a cruel consciência de que o arco-íris é inalcançável: como a ajuda dos políticos, sair da pobreza, deixar

${ }^{27}$ Percebemos aqui uma coincidência entre a conceituação proposta por Carolina sobre a fome como enfermidade "física e moral" com a proposição de Duarte (1986) sobre "perturbações físico-morais" para pensar doenças/sofrimentos que afetam simultaneamente o intra/interpessoal, sendo os meios pelos quais se constrói a noção de pessoa que se realiza como infraestrutura corporal.

Horizontes Antropológicos, Porto Alegre, ano 20, n. 42, p. 21-47, jul./dez. 2014 
a margem do Tietê para "não sofrer o que estamos sofrendo" (QD, p. 48). Vê na sua escrita a possibilidade concreta para alcançar sua transformação, seu devir, definitivo, de escritora: "[...] eu estou escrevendo um livro, para vendê-lo. Viso com esse dinheiro comprar um terreno para eu sair da favela." (QD, p. 25).

Em abril de 1958, Carolina, com 44 anos, encontra Audálio Dantas, repórter da Folha da Noite que vai até a favela do Canindé fazer uma reportagem sobre sua expansão. Por acaso, Audálio escuta Carolina dizer para os "marmanjos da favela": "Vou botar o nome de vocês no meu livro!" (Dantas, 2012). No dia 9 de maio de 1958 o jornal Folha da Noite publica "O drama da favela escrito por uma favelada". Audálio, convencido de que não poderia retratar aquele mundo com a mesma força que Carolina o concebia em seus diários, passa a palavra para Carolina. Esse era o caminho sem volta para Carolina tornar-se escritora.

Audálio compila seus diários e em agosto de 1960 é lançado o livro Quarto de despejo. Carolina, continuando a registrar sua vida em diário, comenta o momento em que lança o livro:

Fui na livraria levar um pouco de terra para por na vitrine. Estava chovendo, fomos de ônibus, quando chegamos na livraria vi o meu retrato na porta. Estou desenhada em ponto grande. E a favela. O que está escrito no quadro? Esta favelada, Carolina Maria de Jesus, escreveu um livro - Quarto de despejo. A livraria Francisco Alves oferece ao povo... Que espetáculo deslumbrante! o povo e os carros paravam para ver o meu retrato galgando. Eu tinha a impressão que era eu que subia para o céu. (Jesus, 1961a, p. 35).

A primeira tiragem de dez mil exemplares se esgota em poucos dias.

Carolina ganha o mundo: Time, Paris Match, Life, Le Monde, jantares com a "sociedade paulistana", viagens para o Uruguai, Chile e Argentina, entrevista no Copacabana Palace, encontro com Clarice Lispector, prefaciada pelo escritor italiano Alberto Moravia. Esse é o seu novo circuito engendrado por sua escrita.

A micropolítica de Carolina, sua luta diária de se opor às condições sociais de existência na favela, dá resultados. Sua contranarrativa, literariamente e literalmente, inscreve a favela Canindé da margem do Tietê no centro da cidade, nas livrarias, no mundo culto e rico do Brasil e de São Paulo, embaralhando as velhas configurações do imaginário social brasileiro sobre o lugar do negro, do pobre, da mulher e da favela.

Trata-se de uma escrita operada pelo corpo enquanto "realidade concreta, vivência prática, conhecimento espontâneo, biografia cotidiana e oralidade

Horizontes Antropológicos, Porto Alegre, ano 20, n. 42, p. 21-47, jul./dez. 2014 
popular" (Richard, 2002, p. 149 apud Carrijo; Santos, 2012, p. 416), em uma palavra: uma escrita que afeta. Uma escrita fraturada: era da favela, porém queria dominar a norma culta como forma de ascensão social pela literatura (Carrijo; Santos, 2012, p. 420; Sousa, 2011, p. 97). Os erros gramaticais e ortográficos de Carolina são, eles mesmos, fraturas expostas da corporificação de sua dor, índices indeléveis de seu traço, de sua condição de existência que se converte em potência escrita ao situar sua perspectiva sobre o mundo. Uma escrita desterritorializada (linguisticamente e socialmente), constituída como "narrativa de resíduos", que "cata", aqui e ali estilos poéticos e literários e experiências de vida (Fernandez, 2008, p. 144). Catando, Carolina "recria e revela" uma narrativa "reciclada, rasurada" de sua existência (Andrade, 2008, p. 40; Fernandez, 2008, p. 139; Sousa, 2004, p. 8).

Essa "montagem" de Carolina operada pelo seu "sofrimento social" produz choques, curtos-circuitos, justaposições que têm a potência de revirar o sentido da língua e do mundo social. A explosiva subjetividade de sua escrita produz seus efeitos no mundo. Sua dor e seu sofrimento tornam-se literalmente sociais e vendem cem mil exemplares, depois, um milhão.

A sociedade brasileira não consegue suportar por muito tempo os paradoxos propostos por Carolina: livro e lixo, escritora e favelada, fama/dinheiro e preta/pobre (cf. Sousa, 2011, p. 96). ${ }^{28}$ Quarto de despejo teve efeito catártico, através dele podíamos sofrer o sofrimento do outro, sofremos com e por Carolina, o Brasil era falado, agora, por uma mulher, negra, pobre e favelada. Essas contradições expõem a conturbada recepção de sua obra e fazem Carolina acumular adjetivações: insubmissa, petulante, geniosa, atrevida, rebelde, transgressora, ousada, agressiva, desafiadora, fracassada, vítima, alegre, corajosa, excepcional, intelectual, louca, indigente, vira-lata (Machado, 2006, p. 106). No âmbito da crítica literária assume também as mesmas contradições gerando polêmicas entre quem a considera escritora e poeta e quem pensava seus diários como "produção das classes subalternas", "escritos dos grupos oprimidos", "subliteratura" (Andrade, 2008, p. 23). ${ }^{29}$

${ }^{28}$ Ver especialmente Meihy (2002) para uma interpretação sobre a ascensão e declínio da obra de Carolina na literatura brasileira.

${ }^{29}$ Para a recepção crítica de Quarto de despejo ver Andrade (2008) e Meihy e Levine (1994). DaMatta (1996), em um artigo no jornal Folha da Tarde, rechaça a negatividade da crítica literária em relação à escrita de Carolina dizendo que Carolina fez sem o saber, esteticamente e sociologicamente, o que os cientistas sociais são treinados para fazer.

Horizontes Antropológicos, Porto Alegre, ano 20, n. 42, p. 21-47, jul./dez. 2014 
É a própria Carolina, quase dois anos depois da publicação de seu Quarto de despejo quem compreende, através de um poema homônimo, o que se passou com ela e o Brasil. Escreve em 6 de novembro de 1961:

Ao publicar o quarto de despejo/Concretizava assim o meu desejo/Que vida. Que alegria/[...] No início veio admiração/O meu nome circulou a Nação/ Surgiu uma escritora favelada/[...] Eu era solicitada/Eu era bajulada/[...]Depois começaram a me invejar/[...]/E assim eu fui desiludindo/O meu ideal foi regredindo/Igual a um corpo envelhecido/Fui enrugando, enrugando/pétalas de rosa murchando, murchando/E... estou morrendo!/[...] Não levo nenhuma ilusão/ porque a escritora favelada/foi rosa despetalada. (Jesus, 1996, p. 151-153).

O Brasil a esquece, mas Carolina "continua a sofrer"; agora "sofre" escrevendo na Casa de alvenaria e depois em seu sítio quando escreve $O$ diário de Bitita, nas poesias ( $O$ infeliz, Desilusão), em seu romance (Pedaço de fome), nas composições (Vedete da favela, O pobre e o rico). Seu escrever é o eterno conhecer pelo sofrimento.

\section{Referências}

ALONSO, M.; TONIOSSO, J. P. Revisitando a cinderela negra: literatura e história em quarto de despejo. HISPECI \& LEMA, n. 1, p. 1-6, 2009.

ANDRADE, L. P. O diário como utopia: Quarto de despejo, de Carolina Maria de Jesus. Dissertação (Mestrado em Letras)-Programa de Pós-Graduação em Letras, Universidade Federal de Mato Grosso do Sul, Três Lagoas, 2008.

BENJAMIN, W. A doutrina das semelhanças. In: BENJAMIN, W. Obras escolhidas: magia e técnica, arte e política. São Paulo: Brasiliense, 1985. p. 108-113.

CABRERA, L. P. Calle y escritura como espacio y campo de acción. El testimonio de Carolina María de Jesús, mujer, negra y cartonera. Polis, v. 25, n. 9, p. 487-513, 2010.

CARRIJO, F. R.; SANTOS, J. B. C. Nas fissuras dos cadernos encardidos: o bordado testemunhal de Carolina Maria de Jesus. (dis)curso, v. 12, n. 2, p. 415-438, ago. 2012. 
CASTRO, E. M.; MACHADO, M. N. Muito bem, Carolina!: biografia de Carolina Maria de Jesus. Belo Horizonte: Editora C/Arte, 2007.

CAVELL, S. Foreword. In: DAS, V. Life and words: violence and the descent into the ordinary. Berkeley: University of California Press, 2006. p. ix-xiv.

CIAVATTA, H. Passagens pelas ruas de São Paulo em narrativas (auto) biográficas. Dissertação (Mestrado em Antropologia Social)-Instituto de Filosofia e Ciências Humanas, Universidade Estadual de Campinas, Campinas, 2013.

CSORDAS, T. Embodiment and experience. Cambridge: Cambridge University Press, 1994.

DAMATTA, R. Carolina, Carolina, Carolina de Jesus... Jornal da Tarde, São Paulo, 11 nov. 1996. Variedades, p. 2C.

DANTAS, A. Tempo de reportagem: histórias que marcaram época no jornalismo brasileiro. Rio de Janeiro: Leya, 2012.

DAS, V. Modernity and biography: womens's lives in contemporary Indian. Thesis Eleven, n. 39, p. 52-62, 1994.

DAS, V. Critical events: an anthropological perspective on contemporary India. New York: Oxford University Press, 1995.

DAS, V. Life and words: violence and the descent into the ordinary. Berkeley: University of California Press, 2006.

DAS NUVENS PRA BAIXO. Produção: Marco Antonio Gonçalves e Geandra Nobre. Direção: Marco Antonio Gonçalves e Eliska Altmann. Rio de Janeiro: Osmose Filmes: UFRJ: UFFRJ, 2014. 1 DVD (77 min).

DELEUZE, G.; GUATTARI, F. O anti-Édipo: capitalismo e esquizofrenia. Rio de Janeiro: Editora 34, 2010.

DERRIDA, J. Of grammatology. Baltimore: Johns Hopkins University Press, 1976. 
DUARTE, L. F. Da vida nervosa nas classes trabalhadoras. Rio de Janeiro: Jorge Zahar: CNPq, 1986.

DUMONT, L. O individualismo: uma perspectiva antropológica da ideologia moderna. Rio de Janeiro: Rocco, 1985.

FERNANDEZ, R. A. Percursos de uma poética de resíduos na obra de Carolina Maria de Jesus. Itinerários, n. 27, p. 125-146, jul./dez. 2008.

GEFEN, A. Introduction à la mimèsis. In: GEFEN, A. La mimèsis: textes choisis. Paris: Flamarion, 2003. p. 13-40.

GONÇALVES, M. A. Etnobiografia: biografia e etnografia ou como se encontram pessoas e personagens. In: GONÇALVES, M. A.; CARDOSO, V.; MARQUES, R. (Org.). Etnobiografia: subjetividade e etnografia. Rio de Janeiro: 7 Letras, 2012. p. 12-37.

HAMBURGER, J. Logique des genres littéraires. Paris: Seuil, 1986.

JESUS, C. M. de Casa de alvenaria. Rio de Janeiro: Livraria Francisco Alves, 1961a.

JESUS, C. M. de. Quarto de despejo. São Paulo: RCA Victor, 1961b. 1 disco sonoro.

JESUS, C. M. de. Quarto de despejo: diário de uma favelada. 9. ed. São Paulo: Livraria Francisco Alves, 1963. (Edição Popular).

JESUS, C. M. de. Meu estranho diário. Organização: R. Levine e J. C. S. B. Meihy. São Paulo: Xamã, 1996.

LAJOLO, M. Poesia no quarto de despejo, ou um ramo de rosas para Carolina. In: MEIHY, J. C. S. B.; JESUS, C. M. Antologia pessoal. Rio de Janeiro: Ed. UFRJ, 1996. p. 37-61.

LEITE LOPES, J. S. O vapor do diabo: o trabalho dos operários do açúcar. Rio de Janeiro: Paz e Terra, 1978.

LEWIS, O. Antropología de la pobreza. México: Fondo de Cultura Económica, 1961. 
LUKÁCS, G. Introdução a uma estética marxista. Rio de Janeiro: Civilização Brasileira, 1978.

MACHADO, M. N. Os escritos de Carolina Maria de Jesus: determinações e imaginário. Psicologia Social, v. 18, n. 2, p. 105-110, ago. 2006.

MAGNANI, J. G. De perto e de dentro: notas para uma etnografia urbana. Revista Brasileira de Ciências Sociais, v. 17, n. 49, p. 11-29, 2002.

MAGNANI, J. G. Etnografia como prática e experiência. Horizontes Antropológicos, ano 15, n. 32, p. 129-156, jul./dez. 2009.

MATURANA, R. H.; VARELA, F. J. Autopoiesis and cognition: the realization of the living. Dordrecht: Reidel Publishing Company, 1980.

MEIHY, J. C. S. B. Subversão pelo sonho: a censura cultural nos diários de Carolina Maria de Jesus. In: CARNEIRO, M. L. T. (Org.). Minorias silenciadas: história da censura no Brasil. São Paulo: EDUSP, 2002. p. 325-345.

MEIHY, J. C. S. B.; LEVINE, R. Cinderela negra: a saga de Carolina Maria de Jesus. Rio de Janeiro: Editora UFRJ, 1994.

NUSSBAUM, M. The fragility of goodness: luck and ethics in Greek tragedy and philosophy. Cambridge: Cambridge University Press, 1986.

PASSEGGI, M. C. A experiência em formação. Educação, Porto Alegre, v. 34, n. 2, p. 147-156, maio/ago. 2011.

PUSSETTI, C.; BRAZZABENI, M. Sofrimento social: idiomas da exclusão e políticas do assistencialismo. Etnográfica, v. 15, n. 3, p. 467-478, jun. 2011.

QUERIDO, A. M. Autobiografia e autorretrato: cores e dores de Carolina Maria de Jesus e de Frida Kahlo. Revista de Estudos feministas, v. 20, n. 3, p. 881-898, dez. 2012.

RICHARD, N. Experiência e representação: o feminino, o latino-americano. In: RICHARD, N. (Org.) Intervenções críticas: arte, cultura, gênero e política. Belo Horizonte: Editora UFMG, 2002. p. 142-155. 
RUFINO, J. S. Os papéis de Carolina Maria de Jesus. [s.d.]. Disponível em: $<$ http://www.almanaquebrasil.com.br/curiosidades-literatura/7377-os-papeisde-carolina-maria.html>. Acesso em: 9 out. 2013.

SARTI, C. A. A vítima como figura contemporânea. Caderno CRH, v. 24, p. 51-61, 2011.

SILVA, J. C. G. História de vida, produção literária e trajetórias urbanas da escritora negra Carolina Maria de Jesus. Trabalho apresentado na $26^{\mathrm{a}}$ Reunião Brasileira de Antropologia, 2006, Porto Seguro, Bahia.

SILVA, J. C. G. Carolina Maria de Jesus e os discursos da negritude: literatura afro-brasileira, jornais negros e vozes marginalizadas. História \& Perspectivas, v. 39, p. 22-37, 2008.

SOUSA, G. H. P. Carolina Maria de Jesus: o estranho diário da escritora viralata. Tese (Doutorado em Teoria Literária)-Instituto de Letras, Universidade de Brasília, Brasília, 2004.

SOUSA, G. H. P. Memória, autobiografia e diário íntimo. Carolina Maria de Jesus: escrita íntima e narrativa da vida. In: BASTOS, H.; ARAÚJO, A. B. (Org.). Teoria e prática da crítica literária dialética. Brasília: Editora Universidade de Brasília, 2011. p. 86-108.

TAUSSIG, M. Mimesis and alterity. London: Routledge, 1993.

TAUSSIG, M. O diabo e o fetiche da mercadoria na América do Sul. São Paulo: Unesp, 2010.

VÍCTORA, C. G. Sofrimento social e a corporificação do mundo: contribuições a partir da Antropologia. RECIIS: Revista Eletrônica de Comunicação, Informação \& Inovação em Saúde, v. 5, n. 4, p. 3-13, 2011.

VOGT, C. Trabalho, pobreza e trabalho intelectual. In: SCHWARZ, R. (Org.). Os pobres na literatura brasileira. São Paulo: Brasiliense, 1983.

WITTGENSTEIN, L. Tractatus logico-philosophicus. London: Kegan Paul, 1932. 
WITTGENSTEIN, K. The blue and brown books. Oxford: Basil Blackwell, 1958.

WITTGENSTEIN, L. O livro azul. Lisboa: Edições 70, 1992.

ZALUAR, A. Condomínio do Diabo. Rio de Janeiro: Editora da Universidade Estadual do Rio de Janeiro, 1994.

Recebido em: 26/12/2013

Aprovado em: 09/06/2014 